\title{
Der Gummidruck
}

\section{Praktische Anleitung}

für

Freunde künstlerischer Photographie

von

\section{Prof. Friedrich Behrens \\ Oberlehrer \\ am Realgymnasium zu Lankwitz b. Berlin}

Mit einer Zweifarbendruckbeilage und mehreren Abbildungen

Dritte verbesserte Auflage

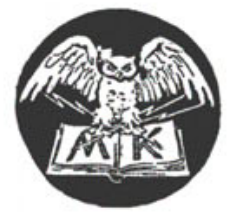

BERLIN W.

$$
\text { Verlag von M. Krayn }
$$

1911 



\section{Inhaltsverzeichnis}

Vorwort . . . . . . . . . . . . . . . . . 5

I. Grundzüge des Gummidruckes . . . . . . . . . . 9

II. Die Anfänge des Gummidruckes . . . . . . . . . 14

III. Die Technik des einfachen Gummidruckes . . . . . . 22

1. Die Materialien . . . . . . . . . . . . . 23

2. Die Präparation des Papiers. . . . . . . . . 45

3. Die Belichtung . . . . . . . . . . . . . 52

4. Die Entwicklung. . . . . . . . . . . . . 55

5. Die Fertigstellung des Abdruckes . . . . . . . 64

IV. Die Technik des mehrfachen und mehrfarbigen Gummidruckes:

A. Das Kopieren von mehreren Negativen . . . . . 68

1. Das Einkopieren von Wolken . . . . . . . . 69

2. Der Kombinationsdruck . . . . . . . . . . 70

3. Der Naturfarbendruck . . . . . . . . . . . 74

B. Das Kopieren von einem einzigen Negative . . . . 75

1. Der mehrfache Druck . . . . . . . . . . . 77

2. Der mehrfarbige Druck . . . . . . . . . . 88

V. Zusammenstellung der verwandten Lösungen . . . . . 93

Alphabetisches Namen- und Sachregister . . . . . . . 95 
